\title{
"Colónida" en el modernismo peruano
}

Como si hubiera pretendido imitar un sello de aguas, CoLóNIDA insertó - sobre el fondo oscuro de las portadas de su primero y segundo números, e impresa con tinta de un pálido color blanco-, la silueta de la "Santa María"; y, a la distancia, los velámenes inciertos de las otras naves que le señalaron a Europa el camino hacia el nuevo continente. Debajo, un retrato de José Santos Chocano, ejecutado por Abraham Valdelomar. Acaso implicaban ambos signos una preferencia por las expresiones y las cosas de América. Tal vez no eran sino vago trasunto de una inquietud que incitaba a dilatar los horizontes. Para averiguarlo, escuchemọs el juicio de José Carlos Mariátegui, partícipe de aquella famosa peripecia literaria. Dice: (I)

"Colónida" no fué un grupo, no fué un cenáculo, no fué una escuela, sino un movimiento, una actitud, un estado de ánimo. El "colonidismo" careció de contornos definidos. Fugaz meteoro literario, no pretendió nunca cuajarse en una forma. No impuso a sus adherentes un verdadero rumbo estético. E1 "colonidismo" no constituía una idea ni un método. Constituía un sentimiento ególatra, individualista, vagamente iconoclasta, im-

(1)--José Carlos Mariátegui: 7 ensayos de interpretación de la realidad peruana. Ediciones : Amauta, Lima - I0ะ8. 
precisamente renovador. "Colónida" no era siquiera un haz de temperamentos afines; no era, al menos propiamente, una generación. En sus rangos, con Valdelomar, More, Gibson, etc., militábamos algunos escritores adolescentes, novísimos, principiantes. Los colónidos no coincidían sino en la revuelta contra todo academicismo. Insurgían contra los valores, las reputaciones y los temperamentos académicos. Su nexo era una protesta, no una afirmación. Conservaron, sin embargo, mientras convivieron en el mismo movimiento, algunos rasgos espirituales comunes. Tendieron a un gusto decadente, elitista, aristocrático, algo mórbido. Valdelomar trajo de Europa gérmenes de d'annunzianismo que se propagaron en nuestro ambiente voluptuoso, retórico y meridional.

La bizarría, la agresividad, la injusticia y hasta la extravagancia de los "colónidos" fueron útiles. Cumplieron una función renovadora. Sacudieron la literatura nacional. La denunciaron como una vulgar rapsodia de la más mediocre literatura española. Le propusieron nuevos y mejores modelos, nuevas y mejores rutas. Atacaron a sus fetiches, a sus iconos, iniciaron lo que algunos escritores calificarían como "una revisión de nuestros valores literarios". "Colónida", fué una fuerza negativa, disolvente, beligerante. Un gesto espiritual de varios literatos que se oponían al acaparamiento de la fama nacional por un arte anticuado, oficial y "pompier".

"De otra lado, los "colónidos" no se comportaron siempre con injusticia. Simpatizaron con todas las figuras heréticas, heterodoxas, solitarias, de nuestra literatura".

$\mathrm{Y}$, ubicando la importancia de la empresa en "el proceso de la literatura peruana", afirma:

"Colónida" representó una insurrección - decir una revolución sería exagerar su importancia- contra el academicismo y sus oligarquías, su énfasis retórico, su gesto conservador, su galantería dieciochesca y su melancolía mediocre y ojerosa. Los "colónidos", virtualmente, reclamaron sinceridad y naturalismo. 
Su movimiento, demasiado heteróclito y anárquico, no pudo condensarse en una tendencia ni concretarse en una fórmula. Agotó su energía en su grito iconoclasta y su orgasmo esnobista".

En la fuerza insurreccional de Colónida y en su espíritu renovador no hubo, sin embargo, intransigencia. "Varios escritores hicieron colonidismo sin pertenecer a la capilla de Valdelomar" —nos dice José Carlos Mariátegui. Y, precisando la alusión, Luis Fabio Xammar agrega: (2)

"Colónida" tenía un amplio eclecticismo intelectual. Acogía en sus columnas posiciones y muestras de las más diversas sensibilidades (por ejemplo Chocano y Eguren), pero esta receptividad no significaba ni ñoñería ni tolerancia culpable para dejar pasar valores de contrabando".

Aún hay otro valor que caracteriza a CoLónIDA: es su reacción contra el desdén con que los escritores capitalinos solían mirar el movimiento cultural de las provincias, su orientación hacia la búsqueda de cauces propios.

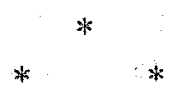

Colónida fué dirigida por Abraham Valdelomar; pero, sin subestimar lo personal de la empresa, se la ha considerado siempre como vocero del "grupo" literario que respondía al mismo nombre. Al respecto, no es muy precisa la información de Luis Alberto Sánchez cuando afirma que al "grupo" Colónida afluyeron voluntarios procedentes de todas partes. Dice que acudieron: (3)

"De Arequipa, con Alberto Hidalgo y César Atahualpa Rodríguez; de Trujillo, con Antenor Orrego, César Vallejo, Alci-

(2).-Luis Fabio Xammar: Tesis doctoral, sobre la obra de Abraham Valdelomar, presentada a la Facultad de Letras de la Universidad Mayor de San Marcos. (Inédita).

3.-Luis Alberto Sánchez: Indice de la poesia peruana contemporánea. Ediciones Ercilla, Santiago de Chile - 1937. 
des Speltucín y Haya de la Torre; de Lima, con José Carlos Mariátegui, César Falcón, Eduardo Zapata López, José Carlos Chirif, Pablo Abril de Vivero; de Puno, con Alejandro Peralta; de Cajamarca, con Nazario Chávez Aliaga".

Pero Alciles Spelucín se encarga de rectificar esta información cuando menciona, con ostensible desencanto, la escasa comprensión que ofrecieron los "colónidos" a los mozos de entonces: (4)

"Nuestra generación, la que apareció en las letras nacionales en momentos de la liquidación "Colónida", se encontró con un lenguaje poético vaporoso y delicuescente. Con los giros y palabras poéticas en boga se expresaban a las mil maravillas los también vaporosos y delicuescentes tópicos poéticos de la época "Colónida". Nuestra falta de dominio sobre la expresión y nuestra impotencia para liberarnos de los lugares comunes de la poesía de entonces, confundieron al principio nuestro "mensaje” con el de la generación precedente. Pero esta confusión duró poco. Los hermanos mayores, los "Colónidos", que nos habían saludado cordialmente, nos negaron después, asegurando que llegábamos a la zona de lo incomprensible o de lo incongruente. Fué entonces cuando nuestra generación se sintió dueña de sí misma, dueña de su expresión y dueña de su estética".

CoLónida dió la impresión de la existencia de un grupo, debido a su eclecticismo y su beligerancia. Atrajo la simpatía de muchos descontentos, porque se enfrentó al academicismo reinante y empezó a divulgar los valores aislados. Adoptó una actitud, plasmando un latente estado de espíritu, y por eso se convirtió en foco, a donde convergieron y de donde irradiaron las energías de los no conservadores. Pero, aparte de José Carlos Mariátegui, Enrique A. Carrillo, Percy Gibson, Augusto Aguirre Morales y otros adherentes circunstanciales, el "grupo" estuvo integrado, fundamentalmente, por aquellos ocho poetas que

(4).-Alcides Spelucín: "Trayectoria Iiteraria de César Vallejo". "Presente": No. 3, Lima. Segundo semestre de I93I. 
reunieron sus composiciones en Las voces muiltiples, a saber: Abraham Valdelomar, Alberto Ulloa Sotomayor, Federico More, Alfredo González Prada, Antonio Garland, Hernán Bellido, Pablo Abril de Vivero, y Félix del Valle. Y -como observaba José Carlos Mariátegui- éstos no formaban un grupo, ni una escuela, ni un cenáculo, ni siquiera una generación. Constituían "la capilla de Valdelomar". Por eso se observa que la agonía de Colónida coincide con el parcial alejamiento de Abraham Valdelomar: en el cuarto número encarga a un administrador -Ernesto More- la atención de los asuntos concernientes a la revista, pero el quinto número no alcanza a ver la luz.

Como consta por el pie de imprenta: los dos primeros números fueron editados en la "Imprenta del Estado", que se hallaba instalada en la calle Núñez, No. 206; el tercero, en los talleres tipográficos de "La Opinión Nacional"; y el cuarto en los talleres de la Empresa Tipográfica "Unión", situados en la calle Boza No. 873. Y chanto se refería a la dirección y la administración era atendido por Abraham Valdelomar, en su propio domicilio, que entonces se hallaba en la calle Ormeño, No. II59; en realidad, no llegó a tener efecto el encargo de estas preocupaciones a un administrador; pues el aviso que así lo establecía no apareció sino en el cuarto número.

Se publicaba en un formato de $17 \mathrm{~cm}$. por $24 \mathrm{~cm}$. 5. Cada ejemplar costaba treinta centavos. $\mathrm{Y}$ a juzgar por una inscripción aparecida en el cuarto número, parece que CoLónida lanzaba 3000 ejemplares.

Fué anunciada como revista quincenal, pero su periodicidad efectiva puede apreciarse en el cuadro siguiente: 


\begin{tabular}{|c|c|c|c|c|c|}
\hline \multirow{2}{*}{ No. } & \multicolumn{3}{|c|}{ FECHA } & \multirow{2}{*}{$\begin{array}{l}\text { Número } \\
\text { de } \\
\text { páginas }\end{array}$} & \multirow{2}{*}{ Observaciones } \\
\hline & $A \tilde{\mathbb{n}} o$ & $\mathrm{M}$ e $\mathrm{s}$ & D ía & & \\
\hline I & \multirow[t]{4}{*}{1916} & Enero & 15 & $3-42$ & \multirow{4}{*}{$\begin{array}{l}\text { Página de arte, con } \\
\text { óleo de Rotı a } \\
\text { Oxandaberro. } \\
\text { Suplemento, con re- } \\
\text { trato de Federico } \\
\text { Gerdes. }\end{array}$} \\
\hline 2 & & Febrero & $I^{0}$ & $3-47$ & \\
\hline 3 & & Marzo & $I^{0}$ & $3-46$ & \\
\hline 4 & & Mayo & $I^{\circ}$ & $3-42$ & \\
\hline
\end{tabular}

Impresa en papel para ilustración, CoLónIDA contaba, también, con variable número de páginas impresas en papel de periódico, dedicadas a la inserción de avisos y a los ecos de la actualidad cultural. Tenía una carátula de cartulina flexible, cuyo color variaba de un número a otro; estuvo ilustrada, sucesivamente, con los retratos de José Santos Chocano, José María Eguren, Percy Gibson - ejecutados al carbón por Abraham Valdelomar-y Javier Prado.

Tenía varias secciones. "La falsa carátula" reemplazaba al editorial, pero sus temas eran intrascendentes. "La quincena literaria" incluía comentarios a los libros del momento. "La quincena teatral" enjuiciaba los espectáculos. "La quincena artística" -que, en rigor, no apareció sino en el tercer númerodebía pasar revista a las exposiciones de arte. Y el "Disparatorio nacional" sacaba a relucir los dislates gramaticales de la prensa. 